\title{
Comunidades obreras portuarias y propensión a la huelga: Iquique, 1923*
}

\section{Dockworkers' communities and propensity to strike: Iquique, 1923}

\author{
Camilo Santibáñez Rebolledo \\ Instituto de Estudios Internacionales de la Universidad Arturo Prat \\ Universidad de Santiago de Chile \\ Comisión Nacional de Investigación Científica y Tecnológica \\ sntibaez@gmail.com
}

(Chile)

\section{Resumen}

Mediante el examen de la prolongada paralización de faenas que protagonizaron los jornaleros marítimos en el puerto de Iquique durante 1923, este artículo discute la tradicional asociación entre la propensión a la huelga de las comunidades obreras portuarias y su supuesto aislamiento social. En su lugar, la hipótesis propone que dicha propensión obedeció a la tensión intrínseca sobre la estructura laboral formada tras la derogación de los gremios decimonónicos, cuyo nudo particular recaía en la nominación de las cuadrillas, confrontando a obreros agremiados con agentes intermediarios en la detentación excluyente por la misma atribución. En concordancia, las conclusiones denotan el modo en que las comunidades obreras sufren laboralmente las transiciones entre las configuraciones del trabajo portuario, recalcando la constitución histórica de su comportamiento reivindicativo y huelguístico.

Palabras Clave: comunidad obrera, propensión a la huelga, trabajadores portuarios, Chile.

\footnotetext{
* Este artículo es una versión reformulada de la ponencia "Comunidad obrera y lucha de clases: la huelga portuaria de Iquique en 1923" presentada en la Mesa 55 "Historia social, comunidades, trabajadores y trabajadoras en Argentina y América Latina, siglos XIX y XX" de las XVI Jornadas Interescuelas/Departamentos de Historia, celebradas los días 9-11 de agosto de 2017 en Mar del Plata, Argentina.
} 


\begin{abstract}
By examining the prolonged strike carried out by Iquique dockworkers during 1923, this paper discusses the traditional association between the propensity to strike of the dockworker communities and their supposed social isolation. Instead, our hypothesis propose that this propensity obeyed to the intrinsic tension on the labor structure formed after the repeal of the nineteenth century guilds, whose particular knot fell to the nomination of the gangs, confronting unionized workers with intermediaries for the exclusive ownership of the same attribution. In agreement, the conclusions denote the way in which dock working communities suffer labor transitions, emphasizing the historical constitution of their protest and strike behavior.
\end{abstract}

Keywords: Workers' community, propensity to strike, dockworkers, Chile.

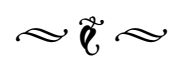

\section{Introducción}

Basándose en la distribución industrial de los días de huelga reportados en diferentes países, los sociólogos Clark Kerr y Abraham Siegel evidenciaron, en un célebre escrito de 1954, que este tipo de conflictividad laboral tendía a concentrarse en la minería, el transporte marítimo y las faenas de estiba. Según propusieron, estas industrias eran particularmente propensas a la huelga por el aislamiento, la homogeneidad y la cohesión que presentaban las comunidades obreras involucradas; cuyas labores, aunque especializadas, carecían de diferenciación ocupacional, impedían la movilidad y favorecían una propagación homogénea del descontento entre sus miembros. Con base en estos presupuestos y respaldados por investigación empírica sobre las condiciones de trabajo en las faenas de estiba, sociólogos como Raymond Charles Miller (1969) llegaron a proponer una "subcultura universal de trabajadores portuarios” (p. 304). La que, entre otros aspectos, se caracterizaba por una extraordinaria solidaridad y una lealtad férrea entre los hombres de los muelles y su comunidad inmediata, además de una severa desconfianza respecto de los agentes foráneos, incluidos los empleadores - con quienes mantenían relaciones particularmente endebles. Todos estos aspectos, insistió Miller en concordancia con Kerr y Siegel, arraigaban en el hecho de que "los estibadores [tendían] a mantenerse socialmente aislados" (1969, p. 309). ${ }^{1}$

Con diferente tiempo de acuse, aunque basadas principalmente en la conflictividad laboral de las comunidades mineras, los presupuestos de Kerr y Siegel fueron objeto de severas críticas. Tanto en lo concerniente a la metodología empleada como al razonamiento y a su base empírica, e igualmente en lo referido a la ligazón entablada entre cultura laboral y propensión a la huelga (Rimlinger, 1959; Edwards, 1977; Church, Outram y Smith, 1991; Manky, 2017).

En lo relativo a los obreros portuarios la reacción crítica parece haber sido bastante más

1. Ver también: Broeze (1991). Todos los textos citados cuya referencia está en inglés han sido traducidos por el autor. 
tardía. Con la excepción del trabajo de Paul K. Edwards (1977, pp. 564-566), fue gracias a los volúmenes Dock Workers. International Explorations in Comparative Labour History que los investigadores contaron con la evidencia suficiente como para concordar en que el "aislamiento" no podía ser asumido como una característica de los obreros portuarios, "ni en su vida cotidiana ni en su acción colectiva". No solamente porque, en su condición de eventuales, estos trabajadores se ocupaban en otras labores, como la pesca y la agricultura, sino también porque dicho presupuesto prescindía de las unidades familiares y de las afinidades raciales, étnicas y migratorias en las que se hallaban involucrados (Davies, Davis, de Vries, van Voss, Hesselink y Weinhauer, 2000, pp. 538-539).

En lo concerniente a la propensión al conflicto, la comparación internacional que Peter Turnbull y David Sapsford (2001) publicaron tras la aparición de Dock Workers parece ser el esfuerzo más logrado por dar un paso adelante en la discusión. Basándose en datos de Estados Unidos, Europa y Australasia, precisaron que la comprensión de la propensión a la huelga de los obreros portuarios ciertamente requería considerar las características fundamentales del proceso de trabajo y la naturaleza eventual del mercado laboral. Pero tal como acusaba la evidencia internacional $-\mathrm{y}$ sobre todo la ausencia de conflicto en lugares con idénticas características-, tales condiciones constituían contextos proclives al estallido de las huelgas, mas no su explicación.

Para determinar por qué en algunos países o puertos las huelgas se convirtieron en constitutivas del trabajo portuario, pero no en otros", sostuvieron, "se [requería además] examinar los acuerdos institucionales (dock labor schemes), las políticas patronales y el rol del sindicalismo (Turnbull y Sapsford, 2001, pp. 233-234).

Resulta curioso, sin embargo, que ambas críticas hayan desplazado su ligazón, dejando en ascuas la relación entre el carácter de las comunidades obreras portuarias y su proclividad a la huelga. ${ }^{2}$ En especial considerando la formación y el rol de las primeras en lo referido a la monopolización y la repartición del trabajo, y especialmente las tensiones que tales comunidades sufrieron en la defensa de dicha prerrogativa durante los períodos previos a la deseventualización (Davis, 2000; Van Voss y Van der Linden, 2000); pues estas devinieron en conflictos bastante emblemáticos en distintas partes del mundo durante el siglo XX (Davis, 2000; Weinhauer, 2000).

Este artículo pretende contribuir a dicho debate mediante el examen de la prolongada huelga portuaria de 1923 en Iquique; cuya comunidad obrera, pese a estar lejos de las características que Kerr y Siegel asumían como causales de la proclividad al conflicto, protagonizó reiteradas y significativas paralizaciones de faenas durante el período 1916-1923 (Santibáñez, 2017a).

La hipótesis es que dicha conflictividad se originó en la tensión impuesta a la comunidad obrera portuaria al hacerla transitar súbitamente de los gremios decimonónicos a la eventualidad. Pues mientras los contratistas intentaron convertirla en un reservorio de fuerza de trabajo subyugada por los capataces a través de la nominación arbitraria de las cuadrillas, los obreros bregaron por recobrar $\mathrm{y}$ administrar la repartición gremial y equita-

2. Una revisión crítica pionera sobre la relación entre comunidad y propensión a la huelga, aunque no referida al caso portuario en particular, en Lincoln (1978). 
tiva del trabajo, contra la intermediación de agentes que consideraban parasitarios de su explotación. Según la hipótesis, dicha tensión derivó en una conflictividad recurrente, protagonizada por obreros agremiados, capataces y contratistas; precisamente porque los tres sabían que el resultado de estos enfrentamientos definiría su propio lugar en la estructura laboral. Cuestión que hizo de la huelga de 1923 el punto álgido de aquella conflictividad.

Para desarrollar esta hipótesis, el subtítulo a continuación esboza la estructura laboral en el puerto de Iquique hacia 1923 y el siguiente resume la evidencia ofrecida por la huelga del mismo año y sus antecedentes.

\section{La formación de la estructura laboral hacia 1923}

Durante 1923, las provincias de Tarapacáy Antofagasta exportaron alrededor de 2.266.000 toneladas de salitre, lo que constituía más del $40 \%$ de la contribución en las rentas ordinarias de la nación. Según el desagregado de 1919, que es el más próximo al que se ha podido acceder, tales provincias se dividían el 55 y $45 \%$ de aquellas exportaciones respectivamente. En el caso de Tarapacá, Iquique exportaba más del $75 \%$ del nitrato producido en la provincia y el $41 \%$ del total. Es decir, tres veces más que los restantes puertos tarapaqueños juntos $(\mathrm{Ca}-$ leta Buena, Junín y Pisagua), y prácticamente lo mismo que todos los puertos de la provincia vecina sumados: Tocopilla, Mejillones, Antofagasta, Caleta Coloso y Taltal. Cuestión que denota la relevancia de Iquique. ${ }^{3}$

3. Las estimaciones se han hecho con base en Hernández, 1930 y Ministerio de Hacienda, 1925.
Imagen 1. Puertos Salitreros, 1923.

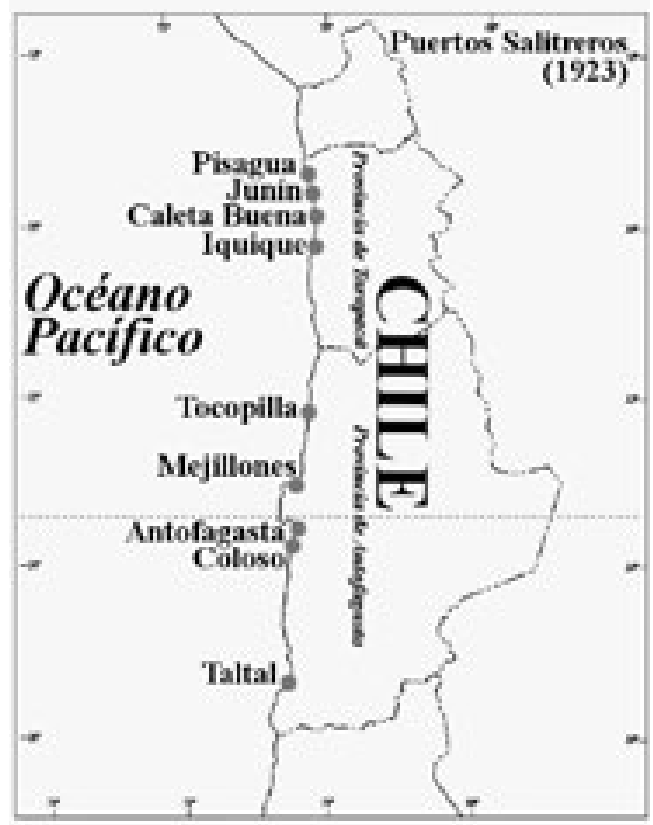

La estructura laboral que regía en las faenas de estiba de este puerto hacia 1923 fue cimentada sobre la derogación de los gremios -organizados y administrados por el Estado- en 1891, y adquirió su fisonomía específica en las fricciones que paralizaron los muelles de manera sucesiva durante las tres décadas siguientes. El trabajo en dichos gremios, monopolizado y a cargo de comandantes designados por el gobierno, estaba organizado en cuadrillas fijas de hombres matriculados, cuyos ingresos dependían de la cantidad del trabajo diario y por tanto de la velocidad con que ejecutaban las faenas. Hasta 1891, además, el ingreso a tales gremios requería antecedentes de comportamiento y verificaciones estrictas por parte de las autoridades (Yávar, 1989; Grez, 2007). 
La nueva fisonomía, en cambio, se basó en la emergencia de los contratistas privados, en el control que estos comenzaron a ejercer tras la derogación del monopolio gremial y en el mecanismo que articularon mediante determinados obreros que se convirtieron en capataces, para reclutar arbitrariamente y proveer de cuadrillas a las empresas involucradas en el tráfico marítimo. En el caso de Iquique, estos capataces organizaron un trust para expedir las tarjetas que habilitaban a los trabajadores en las faenas de embarque, y consiguieron apropiarse del acceso al trabajo en detrimento de los esfuerzos obreros análogos, como el "Gremio Libre de Jornaleros". ${ }^{4}$ Dicho control significó que los capataces manejaran a su arbitrio la nominación de la fuerza de trabajo empleada en las faenas, convirtiéndose en hombres tan determinantes para las ganancias de los contratistas como para los estómagos de los jornaleros. No obstante, también constituyó la principal tensión laboral del período en la región, derivando en paralizaciones de los embarques desde 1916 y particularmente hacia 1919 y 1920 (Santibáñez, 2017a). ${ }^{5}$ Precisamente porque, hasta entonces, como atestiguan los numerosos reclamos obreros e incluso

4. ¿Por qué se organizan los cargadores? (20 de enero de 1917). El Proletario. Biblioteca Nacional (BN), Santiago de Chile. Lo que desempeña un intermediario en las faenas marítimas (12 de octubre de 1921). El Socialista, Antofagasta. BN. Ver también: Pinto Vallejos, 1994, pp. 118-119.

5. Entre la derogación de los gremios decimonónicos y la huelga de 1916 pueden registrarse numerosos conflictos por el mismo motivo en distintos puertos del país. La huelga más temprana con esta reivindicación parece haber sido la que iniciaron los jornaleros iquiqueños en 1893, pero la más conocida es la de Valparaíso en 1903, aunque comúnmente se le atribuyan motivos únicamente económicos. El mismo año se registraron conflictos semejantes en otros puertos, siendo el más significativo el de Antofagasta. Véase: Santibáñez (2017a). los informes gubernamentales, los capataces tendían a privilegiar a determinados hombres en desmedro de otros, acudiendo a estos últimos solo cuando los primeros no daban abasto para el trabajo demandado (Santibáñez, 2019).

En el caso de Iquique, la huelga de jornaleros de 1916 consiguió la instauración del "turno riguroso" o "redondilla parcial"; es decir, la organización gubernamental, numerada y alfabética de las cuadrillas; aunque su formación quedó igualmente a cargo de los capataces. Dado el modo en que se zanjó el conflicto, además, estas cuadrillas terminaron combinando huelguistas con rompehuelgas "en una proporción convenida con [el contratista]". La huelga de julio de 1920, en tanto, consiguió instaurar la "redondilla general"; en la que, según las quejas de los patrones, "la autoridad de los capataces, representantes de los patrones a bordo de los buques, quedó anulada y tomaron la dirección de las faenas los inspectores [obreros] del gremio de jornaleros marítimos", incluyendo el nombramiento rotativo de los trabajadores pertenecientes al mismo. En palabras de las gerencias, y pese a la permanencia de la tutela gubernamental, "los gremios marítimos ejercieron un monopolio sobre el trabajo (...) impidiendo que se ganaran el sustento los que no estaban afiliados a esas organizaciones obreras [y vulnerando la libertad de trabajo garantizada constitucionalmente]"6 (Santibáñez, 2017a).

Demostrando que se trataba de una verdadera tensión, tales quejas patronales consiguieron materializarse en un lockout nacional, abolir la redondilla general hacia 1921 y pautear un de-

6. Régimen de redondilla en la zona salitrera. Julio de 1922. Boletín mensual Asociación de Productores de Salitre. Número 42, Tomo IV, Valparaíso, 1922, pp. 536-540. La fecha original de publicación es del 3 de junio de 1922. 
creto gubernamental para toda la zona salitrera durante el año siguiente, consiguiendo que la distribución de los trabajadores se hiciera "permitiendo a las casas embarcadoras seleccionar su personal". ${ }^{7}$

Pero Iquique fue la excepción. Primero porque la derogación fue momentáneamente pospuesta en 1921, a diferencia del resto de los puertos; y segundo porque, tras dos días de abolida oficialmente la redondilla, en abril de 1922, "[llegó] a la Gobernación Marítima [de Iquique] la contra orden del Ejecutivo de restablecerla en las mismas condiciones anteriores". ${ }^{8}$ Lo que implicaba que la Gobernación Marítima tenía que continuar transmitiéndole al Inspector del Gremio de Jornaleros la solicitud de hombres que hacían las casas embarcadoras y este Inspector "[nombraba] por sí mismo el personal de los que les [tocaba] el turno"; cuestión que los patrones y las autoridades locales resolvieron no tolerar (Santibáñez, 2017a). ${ }^{9}$

Agudizada por el crecimiento de los Industrial Workers of the World (en adelante, IWW) entre la gente de mar, dicha situación abrió una fase de fricciones laborales que alcanzaron su cenit hacia mediados de $1923,{ }^{10}$ cuando el Inspector

7. Solicitud para abolir el régimen de redondilla en Iquique. (noviembre 1922). Boletín mensual Asociación de Productores de Salitre, 47, Tomo IV, Valparaíso, 1923, pp. 1086-1089. También, publicado en el mismo boletín, Reglamento sobre redondilla. (junio de 1922), 42, Tomo IV, Valparaíso 1922, pp. 544-546 y en Diario Oficial (13 de junio de 1922). Número 13303 y en Ministerio de Marina (28 de abril de 1922). Duplicado rectificado, Número 311, Santiago.

8. En las labores marítimas (1 de junio de 1922). El Despertar de los Trabajadores. BN.

9. La redondilla no beneficia a los trabajadores ( $29 \mathrm{de}$ septiembre de 1923). El Nacional. BN.

10. Armonía que no puede existir (9 de septiembre de 1922). El Sembrador. BN; Un nueva arbitrariedad del obrero que llevaba el orden de los nombramientos suspendió durante dos turnos a dos hombres del "Grupo Jeneral de la Redondilla" (Santibáñez, 2018). Suspensión que, según el Gremio, se debía a que los jornaleros adeudaban alrededor de dieciséis cuotas y se habían negado a concurrir a la citación para explicar sus palabras despectivas contra la colectividad. ${ }^{11}$ Más interesante todavía es que la prensa obrera mencionara que uno de los jornaleros castigados era "un empedernido krumiro que [había] carnereado en diferentes huelgas, a consecuencia de lo cual [había] recibido varias veces, en el abdomen, la fría y punzante caricia del cuchillo"; ${ }^{12}$ pues releva el carácter complejo de la comunidad.

Reclamando ser el único facultado para suspender trabajadores, el Gobernador Marítimo le exigió al Inspector obrero que se retractara o pondría al Gremio fuera de la ley; pero los agremiados defendieron al Inspector como única fuente de autoridad. Cuestión que derivó en una nueva paralización de faenas que el Gobernador Marítimo adjudicó automáti-

Gobernador Marítimo (16 de noviembre de 1922) y Un grave conflicto en la bahía provocado por el Gobernador Marítimo (25 de noviembre de 1922). El Despertar de los Trabajadores. Nuestro manifiesto contra la infamia policial (25 de agosto de 1923). El Sembrador. Los gremios marítimos declaran el paro por 24 horas, como protesta contra la actitud del Prefecto y Jefe de pesquisas (22 de agosto de 1923). El Despertar de los Trabajadores. Ver también: Ayer permaneció paralizado totalmente el trabajo en la bahía (23 de agosto de 1923). El Despertar de los Trabajadores y Protesta sindical (25 de agosto de 1923). El Productor. BN.

11. El Gobernador Marítimo Sr. Spoerer declara el lockout al gremio de Jornaleros (2 de agosto de 1923). El Despertar de los Trabajadores.

12. El conflicto Marítimo (4 de agosto de 1923). El Sembrador. 
camente a los wobblies ${ }^{13}$ en el Gremio y a "la facilidad que ofrece la redondilla y su semejanza con un verdadero Soviet en el trabajo”. ${ }^{14}$

Alarmada, la Moneda telegrafió a la Intendencia señalándole que tenía que "[amparar] la libertad del trabajo" y "[el] principio de autoridad [debía] mantenerse en todo caso i por todos [los] medios al alcance". ${ }^{15} \mathrm{Y}$ aunque los lancheros y cargadores locales y de otros puertos se plegaron rápidamente al paro, ${ }^{16} \mathrm{el}$ conflicto se resolvió a los pocos días con la remoción del Inspector obrero y el acuerdo de la rotación mensual de su cargo. ${ }^{17}$ Lo que sugiere que los jornaleros estaban suficientemente conscientes del peligro que pendía sobre el Gremio y la continuidad de la redondilla.

\section{La huelga de 1923}

Si se ignoran los antecedentes esbozados, el detonante de la huelga que estalló el 24 de septiembre y se prolongó hasta el 19 de diciembre, luce bastante desproporcionado. Básicamente, el piloto de un vapor trató de realizar las faenas con menos jornaleros de los conve-

13. Wobblie es el término con que se alude a los miembros de la IWW.

14. Legajos 108-110, s. f., Vol. 1203. Archivo de la Intendencia de Tarapacá (ITAR).

15. S. 1., s. f., Vol. 9-1923. ITAR; El conflicto de la bahía (3 de agosto de 1923). El Despertar de los Trabajadores.

16. La huelga marítima provocada por el Gobernador sigue su curso (9 de agosto de 1923). El Productor. De Pisagua (11 de agosto de 1923). El Despertar de los Trabajadores.

17. Las faenas de la ribera siguen interrumpidas ( $10 \mathrm{de}$ agosto de 1923) y A última hora se soluciona el conflicto en la bahía (10 de agosto de 1923). El Despertar de los Trabajadores. nidos, estos se negaron a trabajar y el Gobernador Marítimo resolvió expulsar al jornalero Francisco Miranda, cuya responsabilidad en el paro la dedujo de su militancia en la IWW. ${ }^{18}$ Los estibadores, lancheros y cargadores se plegaron a la huelga con la misma determinación y rapidez que el gobierno local suprimió la redondilla y con ella el control que el Gremio de Jornaleros ejercía sobre la nominación de los hombres, autorizando a las casas embarcadoras a "organizar por su cuenta las cuadrillas". Cuestión que estas últimas se apresuraron a hacer, abriendo registros durante la misma jornada con la custodia de la policía. ${ }^{19}$

Pese a la supresión, la mantención de la redondilla pareció depender del triunfo o el fracaso de la huelga, lo que irremediablemente encarnizó el conflicto. Contra la argumentación patronal, enfocada en el poder que el monopolio le confería al Gremio de Jornaleros, ${ }^{20}$ la prensa

18. Esta versión de los hechos corresponde a la entregada en Movimiento obrero (29 de septiembre de 1923). El Sembrador. Ciertamente los problemas con el obrero Miranda se arrastraban de antes y se originaban en su condición de wobblie, como puede observarse en Los conflictos marítimos (22 de septiembre de 1923). El Nacional. No obstante, como delata un documento gubernamental fechado el 21 de septiembre de 1923 y también procuraron apuntar los trabajadores, este evento fue la excusa para desplegar una derogación de la redondilla orquestada desde el gobierno central: $\mathrm{La}$ huelga marítima (1 de octubre de 1923). El Nacional. Ver también: En las faenas marítimas (21 de septiembre de 1923). El Nacional y La huelga general de la bahía y la ribera debe ser coronada por un brillante triunfo $(23 \mathrm{de}$ septiembre de 1923) y Un nuevo conflicto marítimo (26 de septiembre de 1923). El Despertar de los Trabajadores.

19. En las faenas marítimas (21 de septiembre de 1923), Aviso (21 de septiembre de 1923) y Se agrava el conflicto marítimo (24 de septiembre de 1923). El Nacional.

20. Debe abolirse la Redondilla (24 de septiembre de 1923). El Nacional. 
obrera local contestó que si la redondilla era abolida, ese monopolio iba a reducirse a los capataces y cien hombres de su agrado; lo que no guardaba coherencia con la reclamada "libertad de trabajo". ${ }^{21}$ Como réplica, el periódico El Nacional-que se convirtió en el vocero de las casas embarcadoras- inició la publicación de una serie de artículos destinados explícitamente a los trabajadores, incitándolos a restarse de la huelga y acusando a los obreros militantes -"socialistas, anarquistas o miembros de la IWW"- de "desquiciadores", que vivían "a expensas de los trabajadores". ${ }^{22}$

El número del 29 de septiembre es particularmente útil para examinar esta línea argumentativa. En un artículo intitulado "La redondilla no beneficia a los trabajadores. Para los trabajadores constituye un perjuicio manifiesto; para sus explotadores, los subversivos, un escudo de defensa", El Nacional planteaba que "la redondilla [constituía] un verdadero monopolio o trust injusto del trabajo, en el que sólo tienen opción un cierto grupo de obreros, como si no fuera natural que todos tengan derecho a competir en la lucha por la vida". "En este grupo", se puntualizaba, "sólo están los que pertenecen al gremio y pagan sus cuotas"; "de esta manera, los dirijentes del gremio (...) tienen bajo su control y manejan mansamente a un grupo de obreros organizados" (sic). La redondilla, en suma, constituía "un sistema despótico y anárquico, en que se ejerce toda clase de abusos de parte de unos cuantos audaces constituidos en Soviet, sobre una masa

21. La huelga general de la bahía y la ribera debe ser coronada por un brillante triunfo (26 de septiembre de 1923). El Despertar de los Trabajadores.

22. Debe abolirse la Redondilla (24 de septiembre de 1923) y ¿Es beneficiosa la redondilla? (24 de septiembre de 1923). El Nacional. de buenos trabajadores, que desean trabajar y verse libre de esa dictadura". ${ }^{23}$

Pese a sus denodados esfuerzos, que incorporaron el ofrecimiento del pago del carnet y la libreta de matrícula a quienes quisieran inscribirse como jornaleros, las casas embarcadoras seguían sin poder conformar las cuadrillas a inicios de octubre. ${ }^{24}$ Cuestión que empujó a la Gobernación Marítima a cursar multas de $\$ 25$ a los obreros que no acudieran a trabajar, a allanar los locales del Gremio de Jornaleros y el de la Unión Local de la IWW, a destruir el periódico de esta última organización y a apresar a una treintena de sus miembros pertenecientes al Gremio -además de un fracasado montaje policial con dinamita. ${ }^{25}$ Lo que alentó a El Nacional a declamar: "Apresados los elementos de la IWW los obreros tranquilos nada tienen que temer", "el Lunes se espera reanudar las faenas". ${ }^{26}$

Sin embargo, esta "salvajada autoritaria burguesa", como la llamaron los obreros, no solo terminaría probando que los trabajadores portuarios no eran títeres de un puñado de wobblies, sino que impulsaría a los comunis-

23. La redondilla no beneficia a los trabajadores ( $29 \mathrm{de}$ septiembre de 1923). El Nacional.

24. Los salitreros no aceptan la restauración (2 de octubre de 1923). El Nacional.

25. El criminal asalto del Jueves 4 (20 de octubre de 1923) y Nuevamente los renegados sayones, el 4 de Octubre (20 de octubre de 1923). El Sembrador.

26. El movimiento huelguista sigue firme (2 de octubre de 1923), El conflicto en la bahía. Un manifiesto del Comité de Huelga (3 de octubre de 1923), Movimiento huelguista en la bahía (5 de octubre de 1923), La nueva salvajada autoritaria burguesa (6 de octubre de 1923). El Despertar de los Trabajadores y La huelga toca a su fin (5 de octubre de 1923), El Nacional. 
tas -pese a su larga rivalidad- ${ }^{27}$ a poner sus recursos a disposición de los huelguistas y de la mantención de la redondilla (Santibáñez Rebolledo, 2017b). Concretamente, los diputados comunistas exigieron una investigación sobre el allanamiento y los presos, y la Federación Obrera de Chile (en adelante, $\mathrm{FOCH}$ ) organizó ayuda económica entre los Consejos mineros. ${ }^{28}$ Hacia mediados de octubre, en tanto, su periódico aludía paralizaciones solidarias en los puertos vecinos y localmente exponía los nombres del puñado de trabajadores que conformaban las cuadrillas de rompehuelgas. ${ }^{29} \mathrm{El}$ Nacional, en tanto, arengaba en un modo particularmente revelador: " $\mathrm{T}$ Trabajadores, ya habéis roto las cadenas de la tiranía de los de tu clase! ¡Un esfuerzo más y vuestros explotadores habrán desaparecido para siempre!" $($ sic $){ }^{30}$

No obstante, el punto de inflexión de la huelga parece haberse producido sobre la misma fecha, pues, en adelante, el aumento en el número de hombres trabajando se hizo irreversible. Cuando se inició noviembre eran más de trescientos entre bodegas, muelles y buques, y las toneladas de salitre embarcado subieron de 1.500 diarias a 2.400; un aumento en el rendimiento que devela que, o se trataba de hombres que habían abandonado la huelga, o eran trabajadores nuevos que adquirieron la

27. Véase también: La separación del obrero marítimo Francisco Miranda es un grosero atentado a la constitución"(25 de septiembre de 1923). El Despertar de los Trabajadores.

28. La Federación Obrera de Chile se adhiere al movimiento huelguista (17 de agosto de 1923). El Despertar de los Trabajadores.

29. El movimiento huelguista a través de los puertos salitreros (16 de octubre de 1923). El Despertar de los Trabajadores.

30. ¡Guerra a los agitadores! (25 de octubre de 1923). El Nacional. experiencia requerida gracias a la prolongación del conflicto. ${ }^{31}$ Por otra parte, el reintegro de los lancheros hacia fines de noviembre hizo ascender el número de obreros a casi novecientos durante mediados del mes siguiente y a 7.450 las toneladas diarias de salitre embarcado. ${ }^{32}$ Esto, pese a "los krumiros [que se marchaban] entre gallos y medianoche", y forzaban al Gobernador Marítimo a "recorrer centros de trabajo ofreciendo trabajo y buenos jornales", a allanar los conventillos donde residían los huelguistas y a obligar a trabajar a "muchachos vagabundos” bajo amenaza de cárcel. ${ }^{33}$

Durante el mismo inicio de noviembre, además, habían sido sofocadas las paralizaciones en Pisagua y Junín. En el primer puerto por el reemplazo con presos comunes y en el segundo por el despido de los dirigentes y el sitio policial. $^{34}$ En estas circunstancias, y con una

31.1200 toneladas de salitre se embarcaron hoy (5 de noviembre de 1923). El Nacional y La gran farsa de los capitalistas sobre los embarques de salitre (27 de octubre de 1923). El Despertar de los Trabajadores.

32. Las faenas de la ribera (21 de noviembre de 1923) y Actividades marítimas (7 y 15 de diciembre de 1923). El Nacional.

33. De la huelga (17 de noviembre de 1923). El Sembrador. "Por la presión de la fuerza se hace volver al trabajo a los obreros de Junín (25 de octubre de 1923), El gobernador marítimo al mando de la fuerza de Granaderos exije (sic) la vuelta al trabajo de los obreros marítimos en sus propios domicilios (14 de noviembre de 1923), Reportaje del ABC de Antofagasta al Diputado Luis V. Cruz sobre los movimientos huelguistas de Iquique y Tocopilla (27 de noviembre de 1923) y El krumiro José Ulloa muere durante las faenas que se realizaban a bordo (29 de noviembre de 1923). El Despertar de los Trabajadores.

34. De la huelga (3 de noviembre de 1923). El Sembrador. Bajo la presión de la fuerza se hace volver al trabajo a los obreros de Junín (25 de octubre de 1923), El estenso (sic) movimiento huelguista en la rejion (sic) salitrera (30 de octubre de 1923) y En Pisagua se está haciendo trabajar a los presos de la cárcel (2 de noviembre de 1923). El 
represión que arreciaba, las movilizaciones en apoyo de los estudiantes y las declaraciones de los mineros de la FOCH sobre hacerse cargo de los hijos de los huelguistas "para que estos continúen luchando", resultaban más conmovedoras que trascendentes. ${ }^{35}$

En el puerto, en tanto, las fricciones entre los huelguistas y los trabajadores que ocupaban su lugar entraron en una dinámica de violencia inusitada. E1 3 de noviembre se registró el primer huelguista muerto a manos de un rompehuelgas armado con un revólver facilitado por la Intendencia y la policía; el día 18 fue asesinado un lanchero del mismo modo y a fines de mes los huelguistas se vengaron, resultando un trabajador muerto y otros heridos a cuchillo y revólver. ${ }^{36}$

Resulta significativo constatar, gracias a las presentaciones realizadas a la comisión gubernamental que arribó a Iquique durante el mismo mes, que "los huelguistas [habían] transigido en parte, aceptando, en vez de la redondilla general, el establecimiento de tres grupos con sus respectivos inspectores y dentro de ellos la

Despertar de los Trabajadores. En las faenas marítimas (24 de octubre de 1923). El Nacional. Los paros de la provincia de Antofagasta no volvieron a ser referidos.

35. Los estudiantes celebraron un mitin en Santiago (2 de noviembre de 1923). El Despertar de los Trabajadores; De la huelga (27 de octubre de 1923). El Sembrador, La policía sigue apresando huelguistas (2 de noviembre de 1923) y Empieza la unión de los esplotados (sic) (9 de noviembre de 1923). El Despertar de los Trabajadores.

36. ¿Quién es el responsable? (3 de noviembre de 1923) y De la huelga (24 de noviembre de 1923). El Sembrador. Nuevamente los atentados (22 de noviembre de 1923) y La cuestión marítima (22 de noviembre de 1923). El Nacional. Ver también: Situación que debe terminar (2 de noviembre de 1923), Los de la I.W.W. siguen asaltando (12 de noviembre de 1923). El Nacional e Infamias que está cometiendo la Policía de orden de la Prefectura (28 de noviembre de 1923). El Despertar de los Trabajadores. redondilla parcial, proponiendo, además, que las casas salitreras se comprometieran a pagar un salario mínimo de 360 pesos mensuales, en caso de que esa cantidad no la alcancen a ganar los trabajadores". Proposición que los capitalistas rechazaron, ofertando mantener los tres grupos, no cancelar ningún salario mínimo y reducir la figura del inspector obrero a la del cabo, cuya función era transmitir reclamos laborales al capataz, sin "ninguna ingerencia en el mando, dirección y repartición de la gente" (sic). Respecto de lo que denominaron "la nombrada" - la designación de turnos a cada obrero-, exigieron que esta fuese hecha por un empleado especial, pagado y designado por ellos. $^{37}$

Para el 10 de diciembre, cuando más de setenta trabajadores eran devueltos a sus casas por estar todos los puestos de trabajo cubiertos, y un número importante de obreros eliminados de las faenas portuarias -particularmente wobblies-, éstas se asumieron normalizadas. ${ }^{38}$ La comunicación gubernamental oficial del término de la huelga estipuló que estas habían quedado "organizadas entre grupos de casas embarcadoras, con un número de trabajadores proporcional a sus embarques", y ratificó que "dentro de cada grupo se [daría] trabajo por estricto orden de turno, para lo cual las firmas han contratado un empleado especial, evitando así que las nombradas queden al capricho de los capataces". ${ }^{39}$

37. La huelga marítima triunfará a pesar de las mentiras de la prensa mercenaria (18 de noviembre de 1923). El Despertar de los Trabajadores.

38. En la bahía (4 de diciembre de 1923) y Hoy trabajaron 617 hombres (10 de diciembre de 1923). El Nacional; Terminación de un conflicto (15 de diciembre de 1923). El Sembrador.

39. Legajos $124-127$, s. f., Vol. 1203. ITAR. Hoy se embarcaron 6,490 toneladas de salitre (14 de diciembre 
En suma, tras noventa días de conflicto, la huelga de 1923 dejó en evidencia que los jornaleros portuarios de Iquique no constituían una comunidad aislada; ni del resto de los obreros del puerto, ni de la ciudad, ni de la región. También dejó en evidencia que en su interior convivían trabajadores con serias cuentas pendientes. Desde 1916, la fuerza de trabajo que constituía Gremio de Jornaleros provenía de una combinación de hombres favorecidos durante años por su fidelidad a los capataces, más otros hombres también agremiados pero desfavorecidos, que paralizaron los embarques por el mismo motivo, y otros cuyo ingreso a los muelles había constituido una suerte de premio por quebrar dichas huelgas. Pese a lo cual, la comunidad evidenció una severa propensión a la huelga durante los siete años siguientes, cuyos resultados incluyeron la instauración de la redondilla, que parecen haber integrado en igualdad de condiciones.

En efecto, fue precisamente dicha fisionomía la que atizó la prensa patronal en 1923, caracterizando a los obreros militantes como explotadores de los trabajadores que no lo eran, llegando a equivalerlos con los capataces en su parasitismo. La IWW parece haber concentrado esta representación periodística tanto como la cólera de la autoridad marítima, pero su influencia en la conflictividad laboral de la bahía iquiqueña fue bastante más restringida que la supuesta por las autoridades (Santibáñez, 2018). Es posible que su presencia en los muelles iquiqueños, creciente durante 1923, precipitara la determinación gubernamental de eliminar la redondilla. Pero, tal como fue apuntado, el asunto se remitía a la estructura laboral misma, tensionada por el espectro gre-

de 1923). El Nacional y El anuncio oficial del fin de la huelga (18 de diciembre de 1923). El Nacional. mial del siglo previo y una costumbre obrera que había cobrado un notorio carácter de clase al oponerse a las prácticas contractuales de los intermediarios.

La decisión gubernamental al respecto, en afinidad con las casas embarcadoras y en perjuicio tanto de los huelguistas como de los capataces y los contratistas (pese a que es bastante probable que alguno de estos intermediarios pasara a ocupar la figura del empleado de "nombradas"), terminó organizando la estructura laboral de modo semejante a la versión gremial; aunque limitando su rol estatal a la fiscalización de la repartición equitativa de los hombres y el trabajo en las casas embarcadoras. Esta prescindencia parece haber sido la principal razón de la prolongación del conflicto, pues según sugiere la utilización de la policía y del propio Gobernador Marítimo en el reclutamiento de la fuerza de trabajo, los intermediarios no estaban cumpliendo dicha función. De este modo, depurándola de intermediarios y "agitadores", el gobierno apostó a extinguir lo que entendió como el foco originario de la propensión a la huelga en el seno de la comunidad obrera.

\section{Conclusiones}

Por intrínseco que parezca el problema de la eventualidad del trabajo portuario en las distintas latitudes costeras, esta condición asume modos históricamente concretos que deben ser estudiados como tales si se pretende indagar en la propensión obrera a la huelga de modo internacional. A este respecto, las advertencias de Turnbull y Sapsford (2001) sobre los acuerdos institucionales, las políticas patronales y el rol del sindicalismo como aspectos que definen 
de modo particular el proceso de trabajo y la naturaleza eventual del mercado laboral, resultan una condición fundamental para la superación de la paradigmática "subcultura universal de trabajadores portuarios" basada en el aislamiento y la homogeneidad (Miller, 1969).

En el caso de la conflictividad laboral protagonizada por los jornaleros del principal puerto salitrero de Chile a inicios del siglo XX, su carácter indica que dicha propensión debe estudiarse atendiendo las consecuencias que tuvo la derogación de los gremios estatales sobre las comunidades obreras preexistentes, centrándose especialmente en lo referido a las prácticas de contratación. Cuestión que, siguiendo el esquema monopolistic-casual-post-casual de Van Voss y Van der Linden (2000), denota la relevancia del estudio de las transiciones entre las principales configuraciones mundiales del trabajo portuario para comprender el comportamiento reivindicativo y huelguístico de su fuerza de trabajo.

De lo previamente señalado se deriva también que la relación entre las comunidades obreras portuarias y la propensión a la huelga no puede ser considerada una cuestión por fuera de las circunstancias históricas particulares de las relaciones laborales que las ligan. Pues la composición -y por tanto el carácter mismode las comunidades obreras está severamente condicionado por dichas relaciones y sus tensiones. Como develó la huelga de 1923, cuyos protagonistas estaban lejos de detentar cohesiones basadas en lealtades largas y férreas, las comunidades obreras portuarias podían comportarse guiadas por su condición de clase en resguardo del trabajo mínimamente asegurado y equitativamente distribuido.<smiles>C=C[Te]=C</smiles>

Recibido: 20-05-2019 Aceptado: 25-09-2019 Publicado: 04-12-2019 


\section{Referencias Bibliográficas}

Broeze, F. (1991). Militancy and Pragmatism: International Perspective on Maritime Labour, 1870-1914. International Review of Social History, 36(2), 165-200.

Church, R., Q. Outram y D. N. Smith. (1991). The Isolated Mass Revisited: Strikes in British Coal Mining. Sociological Review, 39(1), 55-87.

Davies, S., C. J. Davis, D. de Vries, L. H. van Voss, L. Hesselink y K. Weinhauer (Eds.). (2000). Dock Workers. International Explorations in Comparative Labour History, 1790-1970. Aldershot: Ashgate.

Davis, C. J. (2000). Formation of dockers as an occupational group. En S. Davies, C. J. Davis, D. de Vries, L. H. van Voss, L. Hesselink y K. Weinhauer (Eds.), Dock Workers. International Explorations in Comparative Labour History, 1790-1970 (542-559). Aldershot: Ashgate.

Edwards, P. K. (1977). A Critique of the Kerr-Siegel Hypothesis of Strikes and the Isolated Mass: A Study of the Falsification of Sociological Knowledge. Sociological Review, 25(3), 551-574.

Grez, S. (2007). De la "regeneración del pueblo" a la huelga general. Génesis y evolución histórica del movimiento popular en Chile (1810-1890). Santiago: RIL.

Hernández, R. (1930). El salitre. Resumen histórico desde su descubrimiento y explotación. Valparaíso: Asociación de Productores de Salitre en Chile.

Kerr, C. y A. Siegel. (1954). The Interindustry Propensity to Strike: an International Comparison. En A. W. Kornhauser, R. Dubin y A. M. Ross (Eds.), Industrial Conflict (189-212). Nueva York: McGraw-Hill.

Lincoln, J. R. (1978). Community Structure and Industrial Conflict: An Analysis of Strike Activity in SMSAs. American Sociological Review, 43(2), 199-220.

Manky, O. (2017). El lugar importa: efectos de la movilidad en las estrategias sindicales. Revista Mexicana de Sociologia, 79(1), 35-63.

Miller, R. C. (1969). The dockworker subculture and some problems in cross-cultural and cross-time generalizations. Comparative Studies in Society and History, 11, 302-314.

Ministerio de Hacienda (1925). Antecedentes sobre la industria salitrera. Santiago.

Pinto Vallejos, J. (1994). En el camino de la mancomunal: Organizaciones obreras en la Provincia de Tarapacá, 1880-1895. Cuadernos de Historia, 14, 81-135.

Rimlinger, G. V. (1959). International Differences in the Strike Propensity of Coal Miners: Experience in Four Countries. ILR Review, 12(3), 389-405.

Santibáñez, C. (2017a). Los trabajadores portuarios chilenos y la experiencia de la eventualidad: Los conflictos por la redondilla en los muelles salitreros (1916-1923). Historia, 50(2), 699-728. 
Santibáñez, C. (2017b). Documento y antecedentes para el estudio de la relación FOCH-IWW (Iquique, diciembre de 1922). Cuadernos de Historia, 47, 177-182.

Santibáñez, C. (2018). La IWW y el movimiento obrero en Chile: El caso de los portuarios nortinos (19191923). Diálogo Andino, 55, 19-28.

Santibáñez, C. (2019). From the foremen's taverns to 'redondilla' and 'turno numerado': The emergence of the rotating systems at the saltpeter and coal Chilean docks' in the early 20th century. Ponencia preparada para las Maritime Labour History Working Group Sessions, en la Third Conference of the European Labour History Network, Amsterdam, Holanda.

Turnbull, P. y Sapsford, D. (2001). Hitting the Bricks: An International Comparative Study of Conflict on the Waterfront. Industrial Relations, 40(2), 231-257.

Van Voss, L. H. y van der Linden, M. (2000). Dockers' configurations. En S. Davies, C. J. Davis, D. de Vries, L. H. van Voss, L. Hesselink y K. Weinhauer (Eds.), Dock Workers. International Explorations in Comparative Labour History, 1790-1970 (762-780). Aldershot: Ashgate.

Yávar, A. (1989). El Gremio de Jornaleros y Lancheros de Valparaíso, 1837-1859. Etapa de formación. Historia, 24, 319-395.

Weinhauer, K. (2000). Power and control on the waterfront: casual labour and decasualisation. En S. Davies, C. J. Davis, D. de Vries, L. H. van Voss, L. Hesselink y K. Weinhauer (Eds.), Dock Workers. International Explorations in Comparative Labour History, 1790-1970 (580-603). Aldershot: Ashgate. 